\title{
DEVELOPMENT OF INTERNATIONAL TRANSPORT CORRIDORS TO MEET CHALLENGES OF AGRICULTURE
}

\author{
Olga Konnikova ${ }^{1}$, Evgeniy Konnikov ${ }^{1,2}$, Svetlana Bozhuk ${ }^{2}$, Natalia Pletneva ${ }^{2}$ \\ ${ }^{1}$ Saint-Petersburg State University of Economics, Russia; \\ ${ }^{2}$ Peter the Great Saint-Petersburg Polytechnic University, Russia \\ olga.a.konnikova@gmail.com, konnikov.evgeniy@gmail.com, bojuk.svetlana@yandex.ru
}

\begin{abstract}
Globalization processes, welfare global increase and transnational corporation development lead to an increase of the international trade turnover. At the same time, the capacity of existing international transport corridors is limited by natural causes, and the formation and development of new international transport corridors is a lingering and expensive investment process with an unpredictable level of profitability. In this regard, increasing load on the existing international transport corridors leads to efficiency decrease, and the loss of international transport corridor sustainability, which is more dangerous for international trade. These phenomena lead to the necessity of investment in research of sustainability insurance and direction development of these international transport corridors. Of particular importance is the sustainability of the international transport corridor for the agricultural products international trade, since this kind of products imposes a lot of restrictions on their transportation. The key research question is how the dynamics of the international transport corridor development influences on the dynamics of exports of agricultural goods. The purpose of this research is to explore the vectors of world agricultural markets development under the influence of the key international transport corridor transformation. The authors investigated external factors that influence the functioning of the Northern Sea Route, the Trans-Siberian Railway and the Suez Canal. The methodology of this study is based on the classical methodology of the regression analysis. The results of the research were aggregated into an econometric model, allowing to evaluate the impact of changes in the external factors on the development of the studied international transport corridors and, as a result, the development of agricultural product international markets.
\end{abstract}

Keywords: dynamics of exports of agricultural goods, RegARIMA model of agricultural goods exports forecasting, international transport corridor.

\section{Introduction}

Nowadays the total volume of world trade is rapidly increasing. Countries are trying to integrate into this process in order to establish them on the international market or to maintain an existing situation as a manufacturer, exporter or importer. This trend is also valid for agricultural markets. The largest volume of world agricultural exports is provided by the United States. The total market dynamics is mainly determined by the dynamics of the US market. Consequently, for the purpose of studying the vectors of world agricultural markets development under the influence of the key international transport corridors transformation, it is necessary to investigate the specifics of the influence of the external environment on the development of the US agricultural market. Figure 1 shows the dynamics of the US agricultural exports.

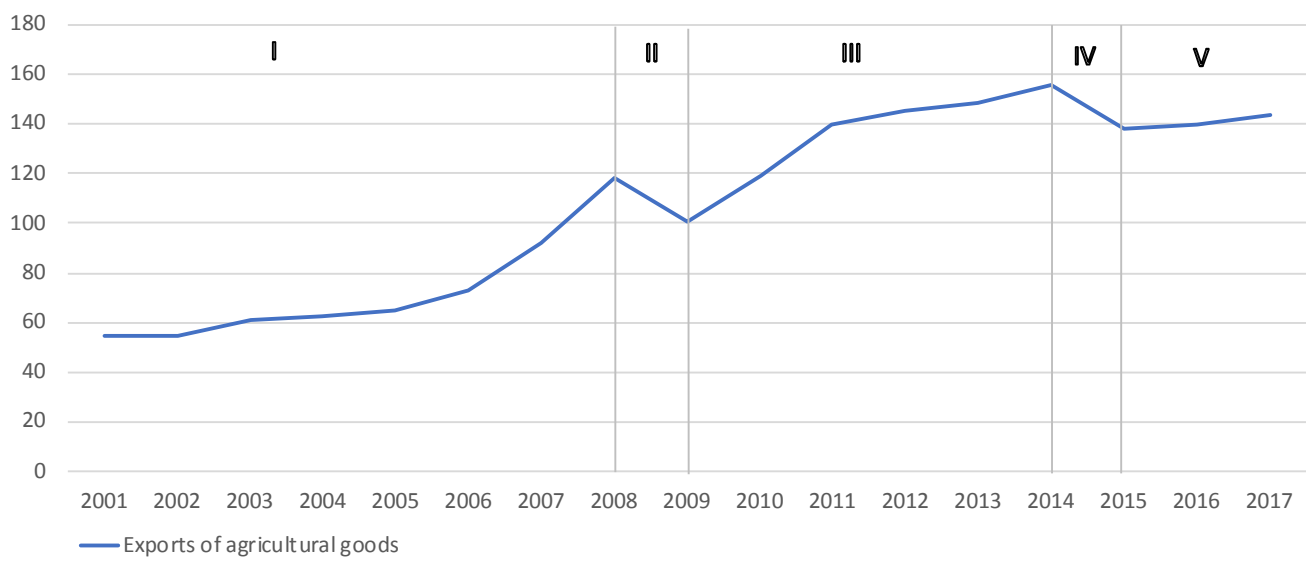

Fig. 1. Dynamics of US agricultural exports (billion USD)

As it can be seen in Figure 1, the exports dynamics of agricultural products has a positive trend in general. However, this trend is not sustainable over time. The relatively long phases of steady growth 
(I, III, V) are periodically replaced by short phases of decline (II, IV). At the same time, the rate of decline is significantly higher than the rate of growth (Figure 2).

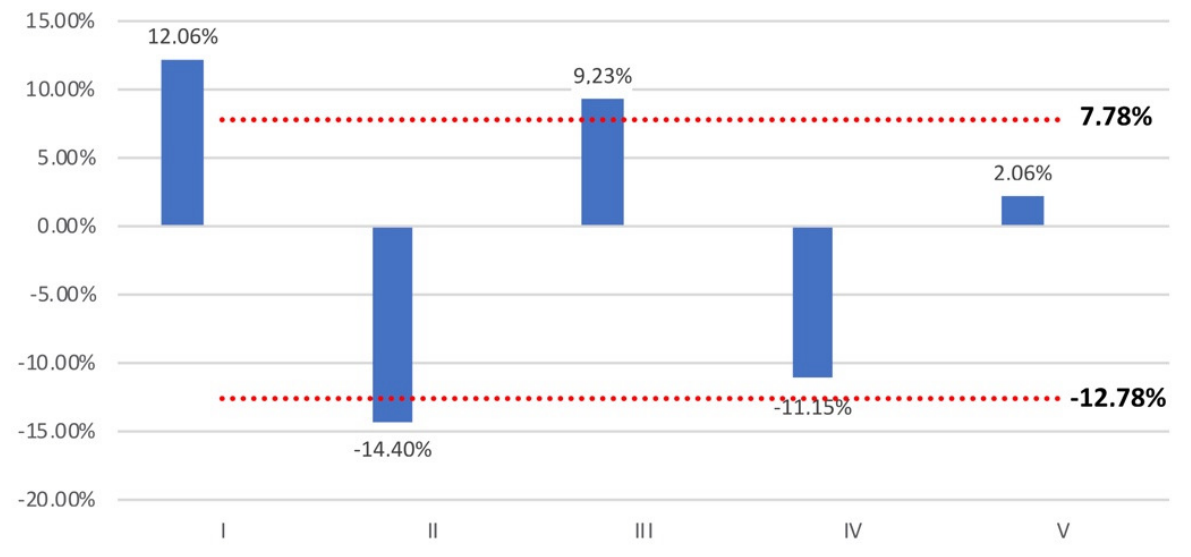

Fig. 2. Dynamics of growth rates of US agricultural exports

This growth pattern indicates the heterogeneous influence of the external environment on the development of international markets for agricultural products. One of the key factors in the development of the world market for agricultural products is the development of international transport corridors. International trade cannot exist without the transport component. That is why new international transport routes (corridors) are being developed to ensure the flow of international trade processes.

The international transport corridor is a direction of concentrated cargo traffic, mastered by one or several transport and technological lines, providing high-quality and on time delivery of export-import and transit cargo [1-7]. Today there are transport corridors such as the Northern Sea Route (Russia), the Suez Canal (Egypt), the Trans-Siberian Railway (Russia), the New Silk Road, the Panama Canal (Panama), the Arctic Bridge (Russia-Canada), and the Northwest Passage (Canada), however, they do not function fully due to geographical features. Each of the mentioned examples has limited bandwidth. Moreover, the stability and efficiency of each of the presented transport corridors is influenced by external factors [8-12]. Consequently, it is possible to put forward a hypothesis regarding the presence of functional connection exports of agricultural products and the dynamics of development of the main transport corridors. The Northern Sea Route, the Suez Canal and the TransSiberian Railway are considered ones of the most developed and frequently used international transport corridors. That is why they present the basis for this study.

The aim of this work is to study the vectors of world agricultural markets development under the influence of the key international transport corridors transformation. To achieve this aim, the authors solved the following tasks:

1. A descriptive research was conducted, based on a study of the existing theoretical basis, the results of which determined the initial set of factors that influence the cargo turnover of the transport corridors under study;

2. A research methodology has been developed;

3. The relationship between the dynamics of exports of agricultural products and the cargo turnover of the transport corridors was described, on the basis of which an effective multiple regression model was built;

4. The linear-functional relationship between the cargo turnover of the transport corridors and the complex of factors was investigated. As a result, a system of regression equations describing this relationship was formed;

5. Models for prediction of regressors of the developed models were formed and a forecast of the turnover of transport corridors was built based on a test sample.

\section{Literature review}

Firstly, it is necessary to investigate the theoretical basis for the formation of a primary complex of factors that can influence the activity of the Northern Sea Route (Russia), the Suez Canal (Egypt) 
and the Trans-Siberian Railway (Russia). In the article entitled "The Northern Sea Route in the System of International Transport Corridors" D. Skripnyuk sets out a methodology for comparing potential transport corridors connecting Northern Europe and Southeast Asia [13;14]. A list of advantages of the transportation of goods through the Northern Sea Route in the future is set. Compared to the Northwest Passage along the Canadian coast, the Northern Sea Route has more competitive advantages. The article shows the results of the comparison of various international transport corridors. It contains the analysis of international transport corridors not by the method of regression analysis, but by a more complex method of using the autoregressive conditional heteroskedaxiality (Arch) model for forecasting. The methodology for the formation of this model can be used in the current study.

In the article entitled "International Transport Corridors and the Arctic" the author K. Kikkas considers potential international transport corridors that could be developed in the Arctic [15]. This article identifies and analyzes the main factors affecting the success of projects to transform the Northern Sea Route and the Northwest Passage into an international transport corridor. A qualitative addition to this article is the work of the author D. Volodin entitled "Russia, Canada and new sea routes in the Arctic" [16]. The source studies and analyzes Canadian and Russian legislation regarding their Arctic waters and the chances of using these routes as alternatives to the Panama and Suez Canals. The transport routes in the Arctic are also considered by N. Chensky in his article "The transport routes of the Arctic: approaches of Russia and the United States" [17]. The author examines in detail the problem of the safety of navigation in the Arctic on the example of the accident of the American tanker Exxon Valdez, which has become the largest disaster in the Arctic. Based on an analysis of the current situation in the Arctic, an analysis is made about the prospects for the development of transport routes in the near future and the interaction between states in matters of security and transport. According to the author, the prospects for the development of transport routes depend on a number of factors. First of all, it is necessary to develop the infrastructure: ports, enterprises, energy facilities, because if the prospects for the Northwest Passage are very restrained, most often, in the context of the American-Canadian disputes over its status, serious commercial use of the passage and the growth of transported goods is not considered. The United States prefers other ways of transporting resources from its own Arctic region, mainly along the west coast of North America. As for the Northern Sea Route, both Russia and other countries (especially the US and China), are showing interest in this project. The success of its implementation lies in a number of aspects, some of which depend directly on the state - creating infrastructure along the route of vessels, simplifying the legislative regime of passage, reducing tariffs, upgrading icebreakers to create better ice conditions. In many ways, the growth of the Northern Sea Route depends on the successful implementation of oil and gas projects on the shelf of the Arctic seas. Due to the difficult economic situation in Russia, a number of projects will most likely be postponed, which will have a negative impact on the prospects for the Northern Sea Route in the near future, so there is no reason to speak of a sharp increase in shipping along the Northern Sea Route in the coming years. A slight increase in the use of the Northern Sea Route is possible due to the implementation of individual fields, as, for example, occurs in the case of the "Prirazlomnoye" oil field. The topic of transport corridors in the Arctic is also raised in the article of D. Skrypnyuk and K. Kikkas entitled "International transport corridors and the Arctic" [18]. The article assesses the potential possibilities of developing the Arctic transport space under conditions of melting polar ice and increasing the time of navigation in the seas of the Arctic Ocean. The article discusses the procedure for building a model of an international transport corridor and analyzes the factors influencing the endogenous variable of the model. The autoregression model of a distributed lag (ADL model) was chosen as a basic research model. Such models are built for the Northern Transport Corridor, Transsib, the transport corridor of the Suez Canal and the Northwest Passage. When constructing models of transport corridors, the volume of goods transported was adopted as the endogenous variable for all corridors. Exogenous variables for each model were selected unique. The exogenous variables selected by the authors may act as exogenous variables in this study.

The topic of the article entitled "Problems of development of international transport corridors in the Russian Federation" by M. Rustamzade and R. Fattakhov is particularly relevant today, since it considers the problems of the development of international transport corridors [19]. In the conditions 
of transition of the leading countries of the world to the innovative way of development, transport is becoming one of the most significant factors of Russia's socio-economic growth, which contributes to strengthening the unity of the economic space of the country, improves interregional and international transport and economic relations, increases the efficiency of natural resources use, develops entrepreneurship and international cooperation, but there are a number of obstacles to the realization of Russia's transport and transit potential. The article describes the features of the development of international and transport corridors in Russia, as well as the key problems of their functioning and possible ways to overcome them. It is said that the lack of funding is related to the lack of conditions for the participation of the private sector in the development of the transport industry. And if private capital is attracted in the construction of roads, there is practically no funding from private investors in the railway sector, with the exception of oil and gas companies that can afford to build new railway lines and only at their own expense. For example, this was done by Gazprom: the construction of $572 \mathrm{~km}$ of the railway on Yamal cost, according to A. Miller, 130 billion roubles. Thus, the development of the main component of transport corridors (including international ones) is influenced by the poor development of transport infrastructure, which is a consequence of the underfunding of this sector. This problem can be solved through public-private partnership mechanisms, such as concession agreements and life cycle contracts. At the same time, private investors should be attracted on favourable terms for them and motivated to perform their work efficiently.

Yu. Lukin in his "Analysis of the Northern Sea Route Activity" [20] states that the problem of the functioning of the Northern Sea Route remains one of the most pressing in the Arctic issues of scientific research and in the practical activities of the Russian state and business related to the use of this transport route. The article contains a SWOT analysis of the Northern Sea Route, a comparative analysis of the cost of flights from Kirkenes to Yokohama via the Suez Canal and using the Northern Sea Route. Its potential, opportunities and existing threats are shown. The operation of the Northern Sea Route under conditions of geopolitical instability, financial and economic crisis, differences in the interests of Arctic stakeholders, the need for a transition to a green economy are analyzed. The main idea of the article is that the Far East, Asia and China are practically defined as the key directions in the state policy of Russia today. However, to realize the geopolitical and economic mission of the Northern Sea Route as a sea transit bridge between Europe and Asia, serious investments, infrastructure upgrades, new ships, cargo flows, navigation safety, high quality of service, positive image of Russia in the Arctic, geopolitical stability, solidarity in the conservation of the arctic environment as well as reasonable economically understandable shippers are needed. The article by R. Bryzgalov entitled "Northern Sea Route: State and Prospects" presents the volumes and range of traffic carried on the NSR nowadays, as well as the prospects of their development under the most favorable conditions [21]. The positive factors working for such a prospect include measures outlined in several state-level policy documents: global warming; a general increase in international shipping; the expediency of the development of mining operations along the Arctic coast of Russia. The constraining factors are: the need for large investments in vehicles and infrastructure, the risk of delays due to particularly difficult Arctic conditions, security questions.

The article by V. Kuvatov, D. Kozmovskiy, N. Shatalova entitled "The potential of the Northern Sea Route of the Arctic zone. Factors and development strategies" shows that there is a trend towards an increase in traffic volumes along the Northern Sea Route [22]. The Northern Sea Route is especially important now, when oil and gas fields are being developed in the Arctic. Russian Federation is expanding its influence in the Arctic at the legislative level. The government adopted such documents as the Strategy for the Development of the Arctic Zone of the Russian Federation, the Law on the regulation of merchant shipping in the waters of the Northern Sea Route. The administration of the Northern Sea Route was also created. The article discusses the most important factors in the development of the Northern Sea Route. Among them are: permanent presence in the Arctic, the development of the infrastructure of the Northern Sea Route, cooperation with other countries. An important role is played by strategic factors associated with the geopolitical and transnational values of maritime navigation in the Arctic zone. Such factors are the control over the marine areas potentially rich in natural resources, the transit significance of the Northern Sea Route as an internal route between the north-western and far-eastern regions of Russia. An important factor is 
the potential growth of transnational transit traffic along the Northern Sea Route between European ports and ports in the Pacific region.

Summing up this section, it is worth saying that each of the transport corridors has its own specifics and operational difficulties of a geographical or political aspect [12;23-26]. A lot of researchers have studied the issue of forecasting the traffic of agricultural products. In particular, Mercedes Campi and Marco Dueñas [24] as well as Russell L Lamb [27] investigated this issue within their national markets. However, they did not consider this issue at the global level in conjunction with the specifics of the joint functioning of international transport corridors. Literature review helped to determine the variables that need to be included in further analysis, among them the cargo turnover; macroeconomic indicators (GDP, exports, imports); the cost of using the International Transport Corridor and some others.

\section{Research methodology}

The methodology of this study is based on the classical methodology of the regression analysis and autoregressive analysis. This methodology implies defining endogenous and exogenous variables of future regression models at the first stage. Cargo turnover for the transport corridor is a key indicator for determining the effectiveness of its operation and its relevance in general. Therefore, this indicator will act as an endogenous variable in this study. The indicators of GDP, exports, imports of the countries that are the main users of a specific transport corridor were taken as independent variables. Also, indicators reflecting the cost of passage through the transport corridor and the number of ships passing through the channel for the Suez Canal, the delivery time for the Trans-Siberian Railway, the number of icebreakers and the minimum ice cover for the Northern Sea Route were used as independent variables. The final set of variables is presented in Table 1. All statistical information is obtained from the statistical portal Quandl (www.quandl.com).

Table 1

Styles used in this template

\begin{tabular}{|c|c|c|c|c|}
\hline No. & Variable & Type of variable & Identification & Measurement \\
\hline 1. & $\begin{array}{l}\text { Cargo turnover on the Trans- } \\
\text { Siberian Railway from China }\end{array}$ & $\begin{array}{l}\text { Endogenous } \\
\text { variable }\end{array}$ & $Z$ & $\begin{array}{l}\text { billion ton- } \\
\text { kilometers }\end{array}$ \\
\hline 2. & China GDP & Exogenous variable & $X_{z}^{1}$ & trillion USD year $^{-1}$ \\
\hline 3. & China imports & Exogenous variable & $X_{z}^{2}$ & 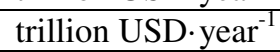 \\
\hline 4. & China exports & Exogenous variable & $X^{3}$ & trillion USD. year ${ }^{-1}$ \\
\hline 5. & Cargo Tariff Index & Exogenous variable & $X_{z}^{4}$ & - \\
\hline 6. & Time of delivery & Exogenous variable & $X_{z}^{5^{2}}$ & days \\
\hline 7. & $\begin{array}{l}\text { Total volume of } \quad \text { cargo } \\
\text { transportation through Northern Sea } \\
\text { Route }\end{array}$ & $\begin{array}{l}\text { Endogenous } \\
\text { variable }\end{array}$ & $Q$ & million tons \\
\hline 8. & Russia GDP & Exogenous variable & $X_{Q}^{1}$ & trillion USD $\cdot$ year $^{-1}$ \\
\hline 9. & Russia imports & Exogenous variable & $X_{Q}^{2}$ & 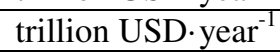 \\
\hline 10. & Russia exports & Exogenous variable & $X_{Q}^{3}$ & trillion USD year $^{-1}$ \\
\hline 11. & Minimum ice cover in the Arctic & Exogenous variable & $X_{O}^{4}$ & million square $\mathrm{km}$ \\
\hline 12. & Number of icebreakers & Exogenous variable & $X_{0}^{5}$ & pcs \\
\hline 13. & EU GDP & Exogenous variable & $X_{0}^{6}$ & trillion USD year $^{-1}$ \\
\hline 14. & EU imports & Exogenous variable & $X_{O}^{7}$ & trillion USD· year ${ }^{-1}$ \\
\hline 15. & EU exports & Exogenous variable & $X_{Q}^{8}$ & trillion USD. year $^{-1}$ \\
\hline 16. & $\begin{array}{l}\text { Transit traffic through the Southern } \\
\text { Sea Route along the Suez Canal }\end{array}$ & $\begin{array}{l}\text { Endogenous } \\
\text { variable }\end{array}$ & $H$ & million tons \\
\hline 17. & EU GDP & Exogenous variable & $X_{H}^{1}$ & trillion USD year $^{-1}$ \\
\hline 18. & EU imports & Exogenous variable & $X_{H}^{2}$ & trillion USD. year ${ }^{-1}$ \\
\hline 19. & EU exports & Exogenous variable & $X_{H}^{3}$ & trillion USD· year ${ }^{-1}$ \\
\hline 20. & Average cost of passage & Exogenous variable & $X_{H}^{4}$ & USD ton $^{-1}$ \\
\hline 21. & $\begin{array}{l}\text { Number of ships passed through the } \\
\text { channel }\end{array}$ & Exogenous variable & $X_{H}^{5}$ & thousand pcs \\
\hline 22. & Exports of US agricultural products & $\begin{array}{l}\text { Endogenous } \\
\text { variable }\end{array}$ & $Y$ & billion USD \\
\hline
\end{tabular}


The structure of relationships between these factors can be represented as a conceptual model (Figure 3).

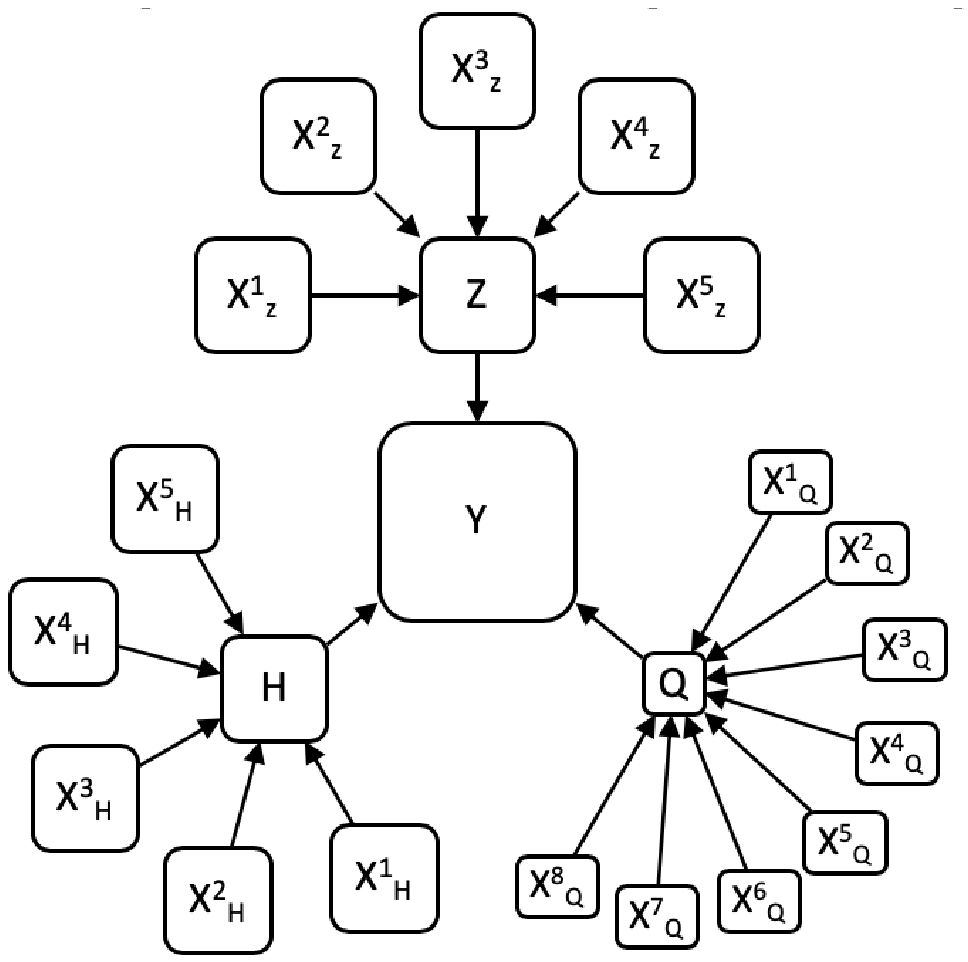

Fig. 3. Dynamics of growth rates of US agricultural exports

When conducting a regression analysis, it is necessary to rely on indicators of how reliable and significant the model obtained in the analysis process is [28-32]:

1. The coefficient of determination used to assess the quality, reliability of a linear relationship. For acceptable models it is assumed that the coefficient of determination must be not less than $50 \%$. Models with a coefficient of determination above $80 \%$ can be considered effective.

2. P-level is an indicator, which value reflects the probability of error when the null hypothesis deviates.

3. Error approximation is used to assess the quality of the resulting model. The regression model is considered to be effective and fairly reliably describing the relationship between the factor and the performance indicator, if the value of the average approximation error does not exceed 10-20\%.

4. The logical nature of the relationship. The direction of the relationship between the variables is determined based on the sign of the regression coefficient. If the sign of the regression coefficient is positive, the relationship of the dependent variable with the independent variable is considered to be directly proportional. If the sign of the regression coefficient is negative, the relationship of the dependent variable with the independent one is inversely proportional.

This study can be algorithmized (Figure 4).

This algorithm is largely automated by specialized software. This study uses the IBM SPSS software product.

\section{Research results}

The primary step in this study is to determine the nature of the relationship between endogenous variables and their potential regressors. This stage consists of the consideration of each transport corridor separately. The training sample is formed from the values of the selected set of indicators for the period 2001-2014. The test sample consists of three consecutive years (2015-2017).

Firstly, we will consider the Trans-Siberian Railway. The Trans-Siberian Railway, the Great Siberian Route (historical name) is a railway through Eurasia, connecting Moscow (the southern passage) with the largest East Siberian and Far Eastern industrial cities of Russia. The length of the highway 
$9298.2 \mathrm{~km}$ makes the Trans-Siberian Railway the longest railway in the world. 5 potential regressors were selected (Table 1).

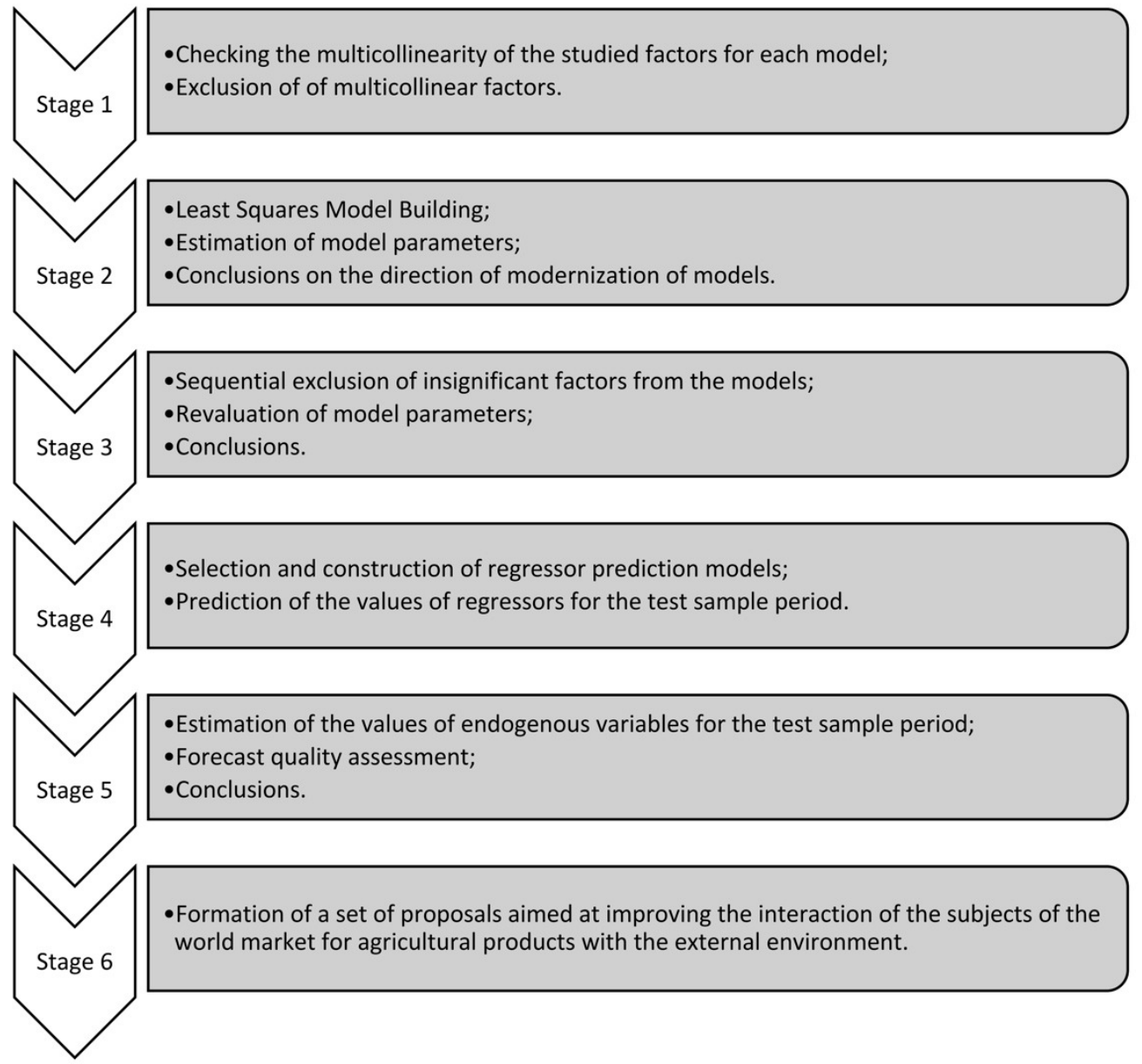

Fig. 4. Algorithm for formation of research results

The selection of indicators in the model was performed using the method "Backwards". The criterion for the exclusion of indicators from the model was the p-level, the boundary value of which was chosen 0.05 . In accordance with the analysis performed, the following model was obtained by means of 4 consecutive iterations of elimination of insignificant regressors:

$$
Z=2472.591+(3.966 E-10) \times X_{Z}^{3}-43.310 \times X_{Z}^{5}
$$

According to this model, it is clear that cargo turnover on the Trans-Siberian Railway is in a direct linear relationship with China export and in the inverse linear dependence on the time of delivery, which does not contradict the formal logic. The coefficient of determination of this model is 0.955 , which shows a strong functional relationship between the variables. Also, on the basis of the ANOVA analysis, it is established that the model is significant in aggregate. The average deviation is $5 \%$, which also suggests a high quality of the description of the dispersion of the result by the dispersion of factors. Figure 5 shows the comparative dynamics of actual and predicted results.

The graph shows that the predicted values accurately enough reflect the actual ones. There are no emissions that fall outside the limits of the confidence intervals. However, in the last period there is a structural gap, indicating possible changes in the specifics of interaction of independent variables with the external environment. Thus, it can be argued that the development potential of cargo turnover on the Trans-Siberian Railway is concentrated in increasing China's exports and increasing the speed of providing transportation services. 


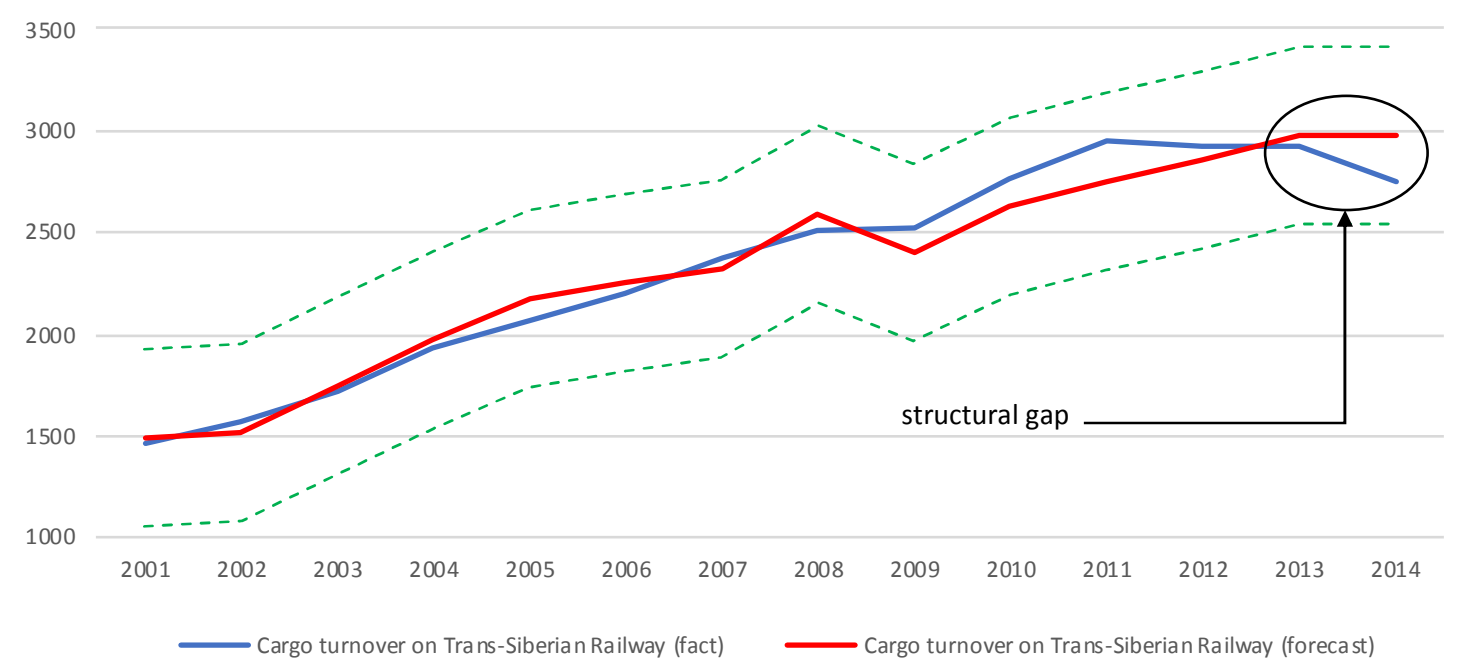

Fig. 5. Dynamics of actual and predicted values of cargo turnover on Trans-Siberian Railway

Next, consider cargo turnover on the Northern Sea Route. The Northern Sea Route (NSR) is the shortest sea route between Europe and East Asia. To study the influence of the external environment on cargo turnover on the Northern Sea Route, 8 potential regressors were selected (Table 1). The methodology of building and optimizing the model is identical to the previous one. In accordance with the analysis performed, the following model was obtained by means of 3 consecutive iterations of elimination of insignificant regressors:

$$
\begin{aligned}
& Q=4.383+13.691 \times X_{Q}^{1}+(-4.881 E-11) \times X_{Q}^{2}+(1.058 E-11) \times X_{Q}^{3}- \\
& -0.547 \times X_{Q}^{4}+0.408 \times X_{Q}^{5}+(-1.846 E-12) \times X_{Q}^{7}
\end{aligned}
$$

This model shows that cargo turnover on the Northern Sea Route depends on a much larger number of indicators than the one on the Trans-Siberian Railway. Conventionally, these indicators can be divided into 3 groups:

1. economic indicators of Russia: Russia GDP, Russia imports, Russia exports;

2. EU economic indicators: EU imports;

3. technical and natural indicators: Number of icebreakers.

Depending on the vector of impact on the result, these indicators can be divided as follows:

1. inverse linearly dependent:

- Russian imports;

- Minimum ice cover in the Arctic zone;

- EU imports.

2. direct-linearly dependent:

- Russia GDP;

- Russia exports;

- Number of icebreakers.

The coefficient of determination of this model is 0.948 , which is an extremely high indicator; the ANOVA analysis showed that the model is significant in aggregate. The average deviation is $9.9 \%$, which is a fairly high result, but not exceeding the permissible limits. Figure 6 shows the comparative dynamics of the actual and predicted results.

The graph shows that the dynamics of cargo turnover on the Northern Sea Route were heterogeneous. At the same time, the quality of the description of the dispersion of the result is rather high, which is confirmed by the absence of significant emissions. However, there were minor structural gaps at the beginning of the study period. Thus, this model can be considered effective. The development of cargo turnover on the Northern Sea Route depends on the dynamics of trade and economic indicators of Russia, the dynamics of EU imports, as well as technical and natural indicators. 


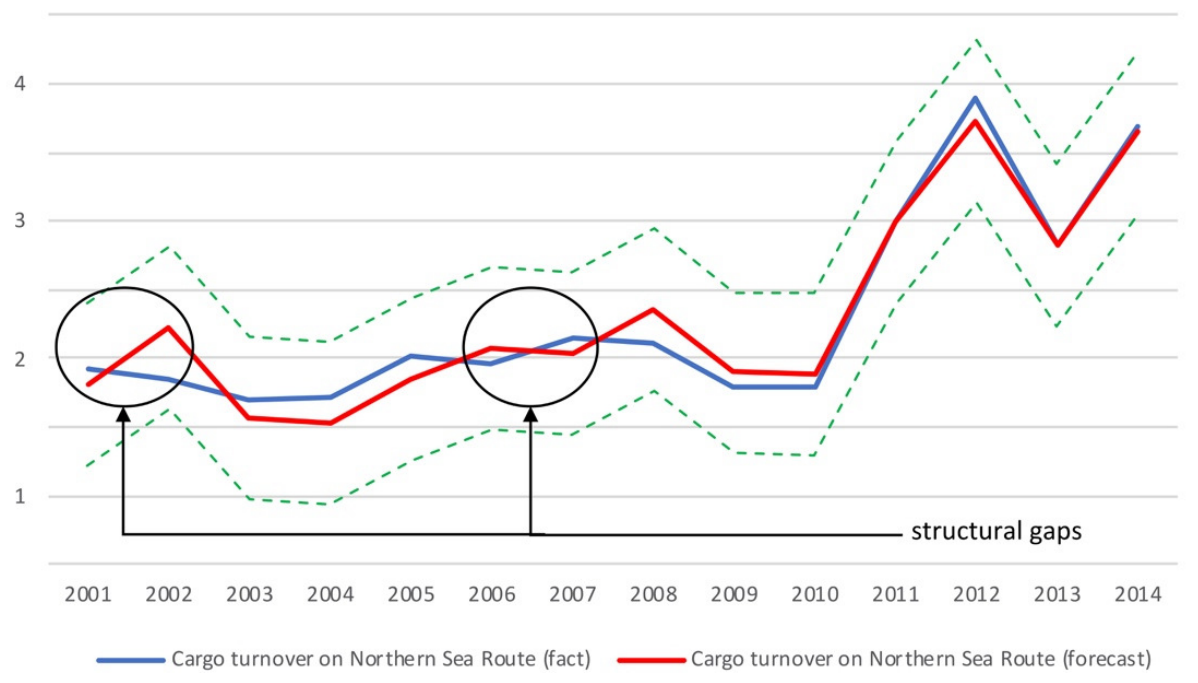

Fig. 6. Dynamics of actual and predicted values of cargo turnover on Northern Sea Route

At the end of this stage of the research, transit traffic through the Southern Sea Route along the Suez Canal is considered. The Suez Canal is an all-water channel in Egypt connecting the Mediterranean and the Red Sea. The channel zone is considered to be a conditional border between two continents, Africa and Eurasia. It is the shortest waterway between the Indian Ocean and the Mediterranean area of the Atlantic Ocean. To study the influence of the environment on the transit traffic through the Southern Sea Route along the Suez Canal, 5 potential regressors were selected (Table 1). In accordance with the analysis performed, the following model was obtained by means of 2 successive iterations of elimination of insignificant regressors:

$$
\begin{aligned}
& H=-206.189+(-2.777 E-11) \times X_{H}^{1}+(-3.755 E-10) \times X_{H}^{2}+(4.574 E-10) \times X_{H}^{3}+ \\
& +39.606 \times X_{H}^{5}
\end{aligned}
$$

According to this model, transit traffic through the Suez Canal is in direct-linear dependence on EU exports and in the inverse-linear dependence on EU GDP and EU imports, which also, like in the case of previous models, does not contradict the formal logic. The coefficient of determination of this model is 0.996, which is the highest indicator among all constructed models. Consequently, the variance of the selected factors explains $99.6 \%$ of the variance of the dependent variable, which indicates the extremely high quality of the model. The average deviation is $1.8 \%$, which is extremely small. Figure 7 shows the comparative dynamics of actual and predicted results.

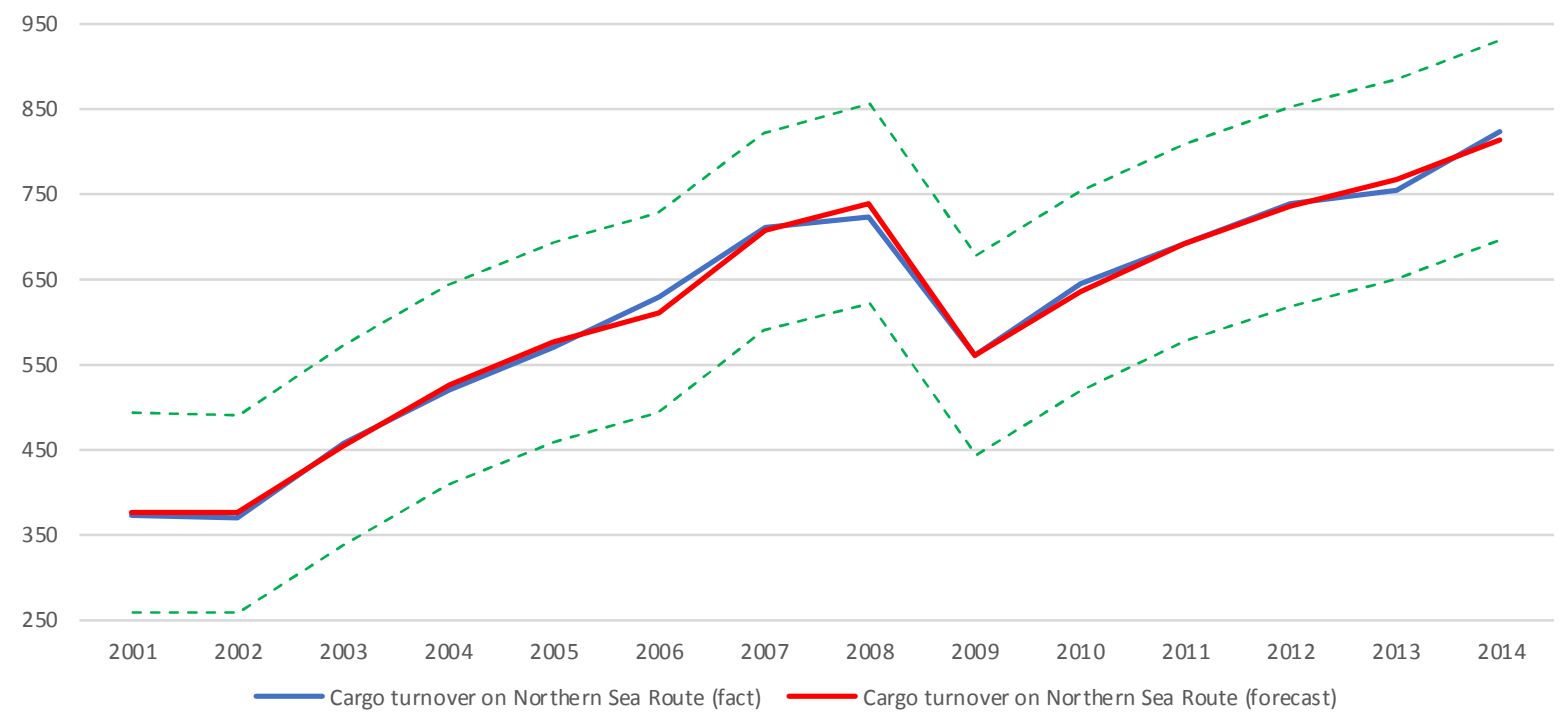

Fig. 7. Dynamics of actual and predicted values of transit traffic through South Sea Route along Suez Canal 
The graph shows that the quality of the description of the actual dynamics of traffic through the Southern Sea Route along the Suez Canal by the dynamics of the factors is extremely effective. There are no emissions and structural gaps. Consequently, traffic through the Southern Sea Route along the Suez Canal is determined by the EU trade and economic indicators and the number of ships passing through the Suez Canal.

All formed models allow to determine the theoretical values of $Z$ (cargo turnover on the TransSiberian Railway), $Q$ (total volume of cargo transportation through Northern Sea Route) and $H$ (traffic through the Southern Sea Route along the Suez Canal). $Z, Q$, and $H$ themselves are potential regressors of $Y$ (Exports of US Agricultural Goods), which is the key to this study. The modeling methodology in this case does not differ from that used previously. In accordance with the analysis performed, the following model was obtained by means of 2 successive iterations of elimination of insignificant regressors:

$$
Y=-64.055+0.54 \times Z+16.338 \times Q
$$

There is no significant stable relationship between the dynamics of traffic through the Southern Sea Route along the Suez Canal and the exports of agricultural goods. While the dynamics of cargo turnover on the Trans-Siberian Railway and Northern Sea Route accounts for $94 \%$ of the variance of exports of agricultural goods. At the same time, the standardized regression coefficient for $Q$ is 0.317 , and for $Z$ it is 0.729 , which indicates the unequal influence of the factors in the model. Figure 8 shows the comparative dynamics of actual and predicted results.

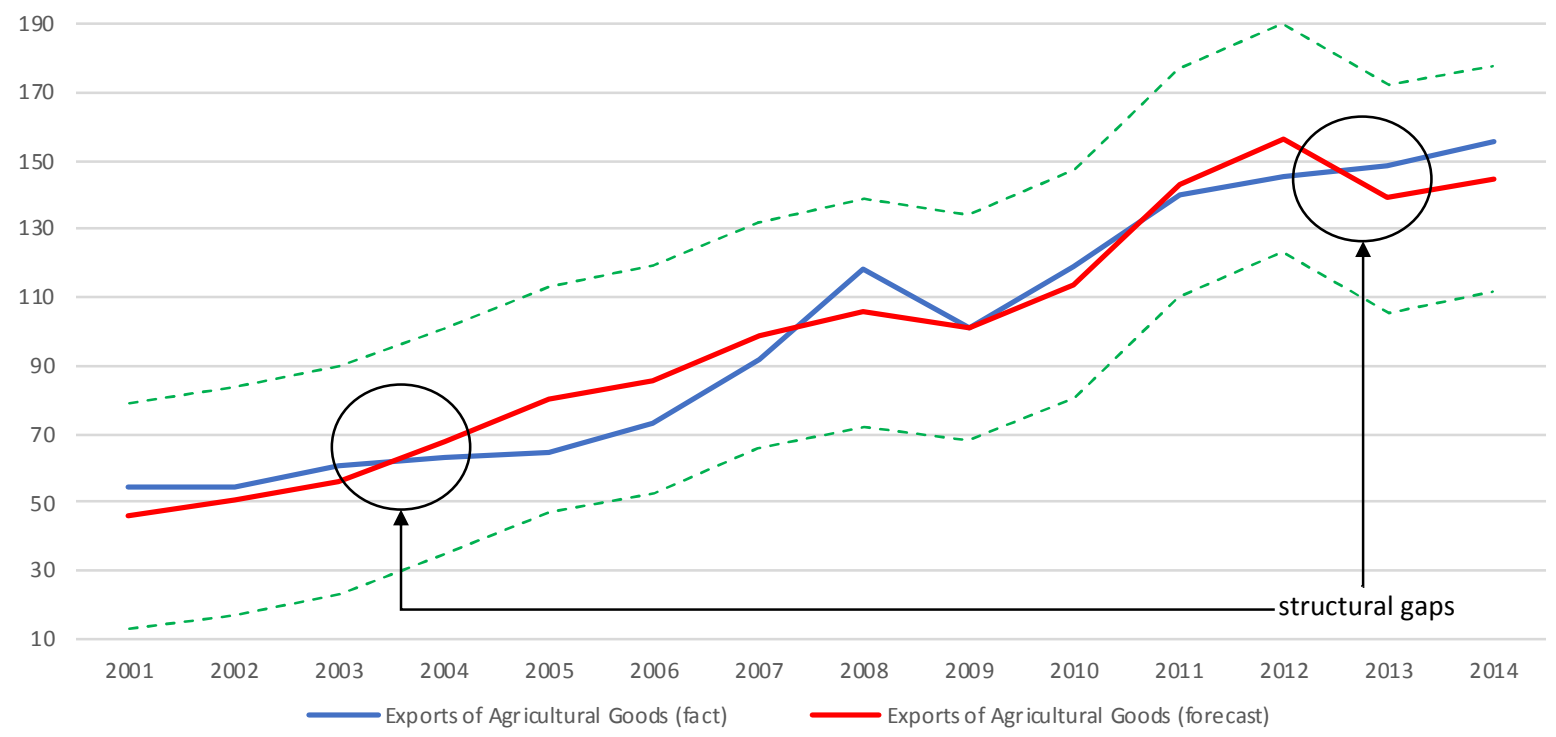

Fig. 8. Dynamics of actual and predicted values of exports of agricultural goods

The graph shows no significant emissions, and, despite the structural gaps at different intervals of the studied period, this model can be considered effective. The proportion of the described variance is more than sufficient. The analysis made it possible to optimize the theoretical conceptual model presented in Figure 3. The confirmed conceptual model is presented in Figure 9.

The presented model is subject to testing on a test sample (period 2015-2017). However, the absence of current statistical information allows to modify this task. The authors propose to predict the values of the second order regressors ( $X$ regressors) based on the study of their dynamics (without taking into account the influence of the external environment).

To solve this problem, the most effective models are the ones of ARIMA class. Further, it is proposed to supplement the training sample with predicted values and to rebuild the generated regression models $Z$ and $Q$ by including the retrospective dynamics of the corresponding dependent variables (models of the RegARIMA class). 


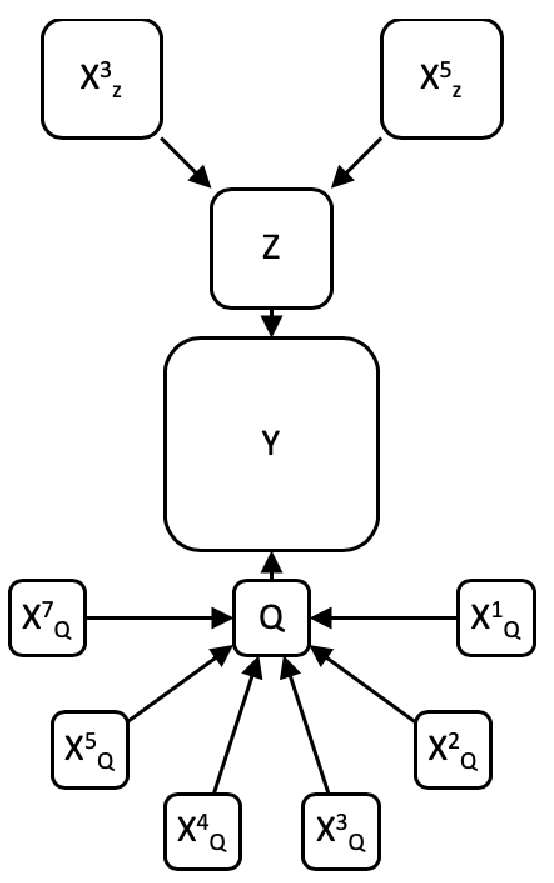

Fig. 9. Confirmed conceptual model

In conclusion, it is proposed to construct a forecast of $Y$ values for the period 2015-2020, also on the basis of the model of the RegARIMA class, containing both $Z$ and $Q$ as regressors, as well as autoregressive components and moving average components. The resulting models can be formed into a system of econometric equations:

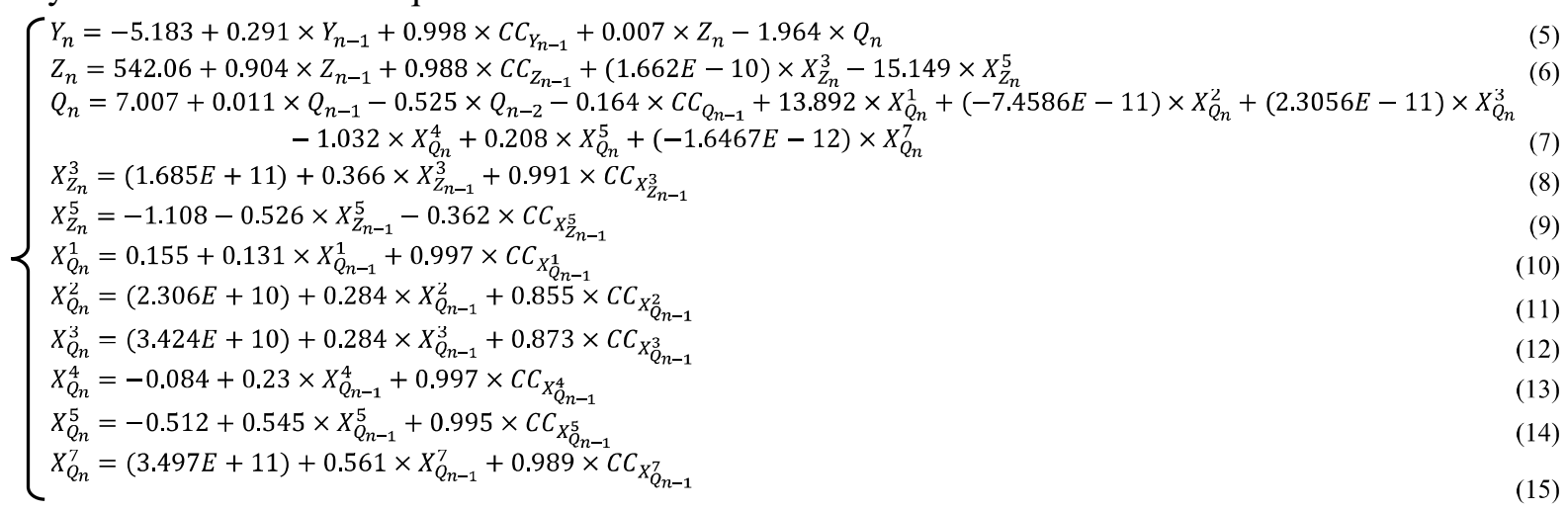

Some factors have changed the vector of their influence (in particular, the factor $Q$ ). The algorithm for applying this system of equations is presented in Figure 10.

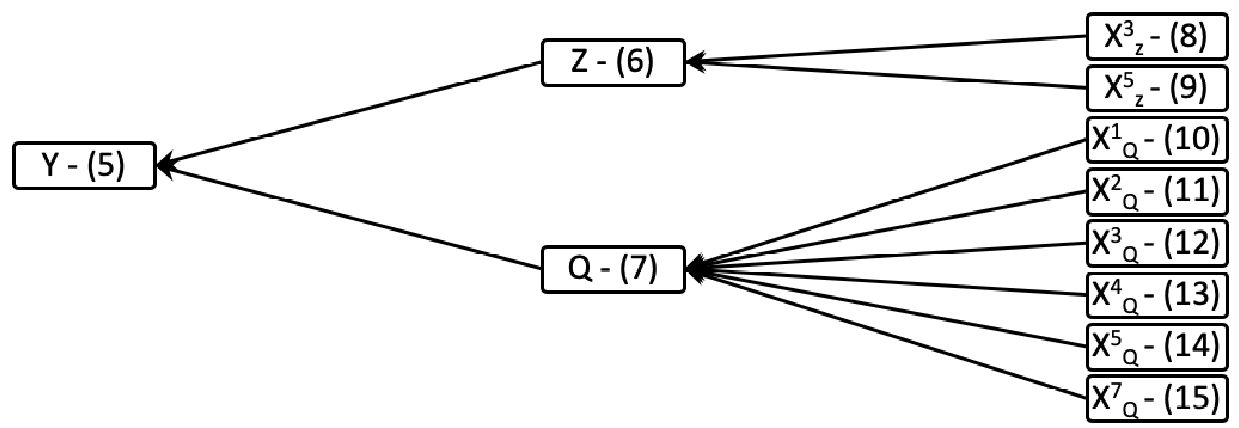

Fig. 10. Forecasting algorithm of exports of agricultural goods 
The coefficients of determination of these models are in the range from 0.85 to 0.97 , which allows to consider this system of equations as effective. The significance of each of the models is also at the required level. Figure 11 shows the comparative dynamics of the actual and predicted result $Y$, in accordance with the model (5).

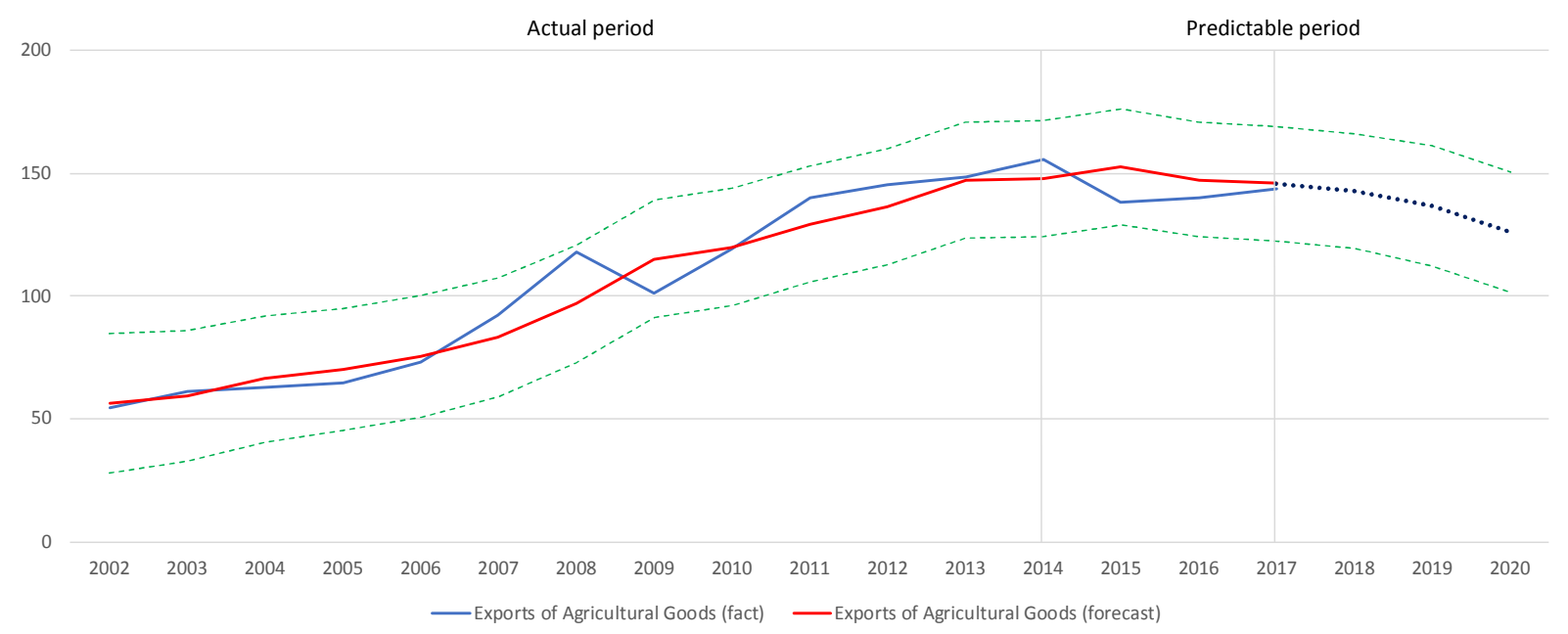

Fig. 11. Dynamics of exports of agricultural goods (model (5))

The graph shows that the quality of the approximation is quite high (there are no emissions and significant structural gaps). At the same time, the forecast for the development of agricultural exports is rather pessimistic. In the forecast period, there is a gradual decline in exports to the level of 20102011. The reason for this decline in the first place is the rapid development of the Northern Sea Route. This phenomenon is ambiguous and requires in-depth research.

\section{Discussion}

The developed forecast indicates a gradual decline in agricultural exports. However, the methodology of this study allows to draw unobvious conclusions. Since the export of agricultural products of the United States acted as an indicator of the development of the global agricultural market, we can interpret the resulting development trend from two sides: either global exports of agricultural products will decline (which is unlikely due to demographic dynamics), or the share of the United States in world agricultural exports will decline. The second hypothesis is much more plausible.

In the first place, such dynamics are provided by the dynamic development of the Northern Sea Route. According to the obtained results, the turnover of the NSR should grow exponentially over the entire forecast period. This is primarily affected by the increment of Russia GDP and Russia exports, as well as the decline in Russia and EU imports in absolute units. This effect is determined by the depreciation of the national currency of Russia against dollar and the constantly settling down sanction and anti-sanction effects. The influence of these factors leads to a restriction of the ability of Russia to import various groups of products (primarily agricultural), which leads to the need to dispel its own production. At the same time, it is necessary to take into account the constantly growing needs of China, which does not take part in the sanctions pressure on Russia. As a result, trade relations between Russia and China may develop under the influence of the multiplicative effect of reducing the cost of imported products due to [22;33-34]:

1. dynamics of the exchange rate;

2. improving the efficiency of production, due to both the economies of scale and domestic investment in its own production;

3. improving the efficiency of transportation through the development of the infrastructure of the main transport corridors (in particular, the Northern Sea Route).

This multiplier effect is primarily true for the agricultural market, since the process of transporting these products is sensitive to physical and time parameters. Thus, the existing international pressure contributes to the development of the Northern Sea Route as an international transport corridor 
between Russia and China, and (as a result) to reduce the share of the United States as a global exporter of agricultural products. In this case, China is the key beneficiary, since it receives a more sustainable and efficient international transport corridor for the purpose of exporting and importing various product groups (primarily agricultural products).

Despite the fact that this trend is positive for some countries, its impact on the global agricultural market is strictly negative. Any restriction of trade flows leads to a decrease in the level of competition in the world markets as a whole, and the formation of closed trade coalitions that do not operate according to market laws. As a result, the total volume of the open world market for agricultural products decreases, which leads to a decrease in the efficiency of both production and transportation of agricultural products. However, such phenomena lead to the development of local transport corridors (like the Northern Sea Route). Thus, the development of the world market for agricultural products is dialectical in nature, and is manifested in two multidirectional processes:

1. development of international transport corridors through the formation of an open competitive market;

2. development of international transport corridors due to the need to interact within the framework of closed trade coalitions.

Both processes are aimed at the development of international transport corridors but are multidirectional at the same time. At the moment, the current policy of key market participants contributes to the development of international transport corridors through the second path. In order to increase sustainability and maintain the current balance between key players, it is necessary to increase market openness and integrate developing countries into international trade relations. Another way, also aimed at increasing sustainability and maintaining the current balance between key players, is the investment by key players of the open market in the development of closed transport corridors in order to get return on investment and/or to get partial integration into the trade process within these corridors.

\section{Conclusions}

In this article the authors investigated the vectors of world agricultural markets development under the influence of the key international transport corridor transformation. The obtained statistical forecasting models suggest that the current dynamics of development of international transport corridors contributes to a systematic change in the balance between key agricultural exporters in the world market. This is primarily due to the development of the Northern Sea Route. In order to increase market sustainability and maintain the existing balance between key participants, it is necessary to increase the level of openness of the international market for agricultural products, in particular, by easing sanctions and improving international currency legislation. The key vector for the development of this study is the analysis of key areas for balanced development of international transport corridors, where the objective function is determined by maximizing the agricultural goods turnover.

\section{Acknowledgment}

The research is carried out with the financial support of the grant from the Program Competitiveness Enhancement of the Peter the Great St. Petersburg Polytechnic University, Project 5100-2020.

\section{References}

[1] Didenko N.I., Cherenkov V.I. Economic and geopolitical aspects of developing the Northern Sea Route. IOP Conference Series: Earth and Environmental Science, vol. 180 (1), 2018.

[2] Didenko N.I., Kulik S.V. Environmental Shocks: Modelling the Dynamics. IOP Conference Series: Earth and Environmental Science, vol. 180 (1), 2018.

[3] Didenko N.I., Romashkina E.S. Assessment of the Influence of the Extraction of Energy Resources on the Environment. IOP Conference Series: Earth and Environmental Science, vol. 180 (1), 2018. 
[4] Didenko N.I., Skripnuk D.F., Kikkas K.N. etc. Innovative and technological potential of the region and its impact on the social sector development. Proceedings of International Conference on Information Networking, January, 2018, pp. 611-615.

[5] Didenko N.I., Skripnuk D.F., Kikkas K.N. etc. The analysis of convergence - Divergence in the development of innovative and technological processes in the countries of the Arctic Council. Proceedings of International Conference on Information Networking, January, 2018, pp. 626-631.

[6] Didenko N.I., Skripnuk D.F., Mirolyubova O.V. etc. System of econometric equations of the world market of natural gas. Proceedings of International Conference on Information Networking, January, 2018, pp. 217-222.

[7] Gazizulina A.Y., Mirolyubova O.V., Konakhina N.A. etc. Problems of forming requirements to training of specialists for industrial and economic complex. Proceedings of 2017 IEEE 6th Forum "Strategic Partnership of Universities and Enterprises of Hi-Tech Branches (Science. Education. Innovations)", January, 2018, Saint-Petersburg, Russia, pp.196-198.

[8] Dvas G.V., Dubolazova Y.A. Development and business support of innovative enterprises in the Russian Federation. Proceedings of the 31st International Business Information Management Association Conference, IBIMA 2018: Innovation Management and Education Excellence through Vision 2020, 2018, pp. 5654-5657.

[9] Gutman S., Rytova E., Kravchenko V. System of regional indicators for sustainable development of the far North regions. Proceedings of the 31st International Business Information Management Association Conference, IBIMA 2018: Innovation Management and Education Excellence through Vision 2020, 2018, pp. 1843-1852.

[10] Gutman S., Zaychenko I., Rytova E. Development strategy of Far North transport infrastructure: Problems and prospects. Proceedings of the 29th International Business Information Management Association Conference - Education Excellence and Innovation Management through Vision 2020: From Regional Development Sustainability to Global Economic Growth, 2017, pp. 14391449.

[11] Klochkov Y., Gazizulina A., Golovin N. etc. Information model-based forecasting of technological process state. Proceedings of 2017 International Conference on Infocom Technologies and Unmanned Systems: Trends and Future Directions, ICTUS 2017, January, 2017, pp. 709-712.

[12] Rudskaya I.A., Rodionov D.G. Comprehensive evaluation of Russian regional innovation system performance using a two-stage econometric model. Espacios, vol. 39 (4), 2018.

[13] Skrypnyuk D.F. Northern marine way in the system of international transport corridors. Proceedings of International scientific conference Arctic: history and modernity, April, 2014, pp. 509-518.

[14] Exports of agricultural goods. Quandl - Federal Reserve Economic Data. [online] [20.04.2019]. Available at: https://www.quandl.com/data/FRED/B181RC1A027NBEA-Exports-of-agriculturalgoods.

[15] Kikkas K.N. International transport corridors and the Arctic. Modernization. Innovations. Development), vol. 6(3), 2015, pp. 178-184.

[16] Volodin D.A. Russia, Canada and new sea routes in the Arctic. Moscow: Institute of the USA and Canada, pp. 53-70.

[17] Chensky N.A. Transport ways of the Arctic: approaches of Russia and the USA. Azimuth of scientific research: economics and management, 2015, pp. 87-91.

[18] Skrypniuk D.F., Kikkas K.N. International transport corridors and the Arctic, pp. 59-72.

[19] Rustamzade M.N., Fattakhov R.V. Problems of development of international transport corridors in the Russian Federation. Interactive science, 2015, pp. 165-167.

[20] Lukin Yu. F. Analysis of the Northern Sea Route. Bulletin of MSTU, vol. 3, 2015, pp. 467-475.

[21] Bryzgalov R.A. Northern Sea Route: state and prospects of development. Modernization. Innovations. Development, vol.5, 2011, pp.103-106.

[22] Rybakov D.S. A process model of a logistics system as a basis for optimisation programme implementation. International Journal of Logistics Research and Applications, vol.21(1), 2018, pp. 72-93.

[23] Leksin V.N., Profiryev B.N. Socio-economic priorities for the sustainable development of Russian arctic macro-region. Economy of Region, vol.4, 2017, pp. 985-1004. 
[24]Campi M., Dueñas M. Intellectual Property Rights and International Trade of Agricultural Products. World Development, vol. 80, 2016, pp. 1-18.

[25] Nikolova L.V., Rodionov D.G., Litvinenko A.N. Sustainability of the business in the conditions of globalization. Proceedings of the 30th International Business Information Management Association Conference, IBIMA 2017 - Vision 2020: Sustainable Economic development, Innovation Management, and Global Growth, January, 2017, pp. 417-421.

[26] Romashkina G.F., Didenko N.I., Skripnuk D.F. Socioeconomic modernization of Russia and its Arctic regions. Studies on Russian Economic Development, vol. 28(1), 2017, pp. 22-30.

[27]Lamb R.L. Food crops, exports, and the short-run policy response of agriculture in Africa, Agricultural Economics, vol. 22, iss. 3, 2000, pp. 271-298.

[28] Gutman S., Kozlov A., Teslya A. Sustainable development of industrial enterprises in oneindustry towns through harmonization of main stakeholders' interests: Case of Russian arctic zone. Proceedings of the 31st International Business Information Management Association Conference, IBIMA 2018: Innovation Management and Education Excellence through Vision 2020, 2018, pp. 3014-3023.

[29] Ilin I.V., Iliashenko O.Y., Klimin A.I., Makov K.M. Big data processing in Russian transport industry. Proceedings of the 31st International Business Information Management Association Conference, IBIMA 2018: Innovation Management and Education Excellence through Vision 2020, 2018, pp. 1967-1971.

[30] Kichigin, O.E. Fossil fuel production impact on regional eco-economic development. International Journal of Ecological Economics and Statistics, vol. 38(4), 2017, pp. 12-22.

[31] Klochkov Y., Klochkova E., Krasyuk I. etc. An approach to decrease the risk of losing customers. Proceedings of 6th International Conference on Reliability, Infocom Technologies and Optimization: Trends and Future Directions, ICRITO 2017, January, 2018, pp. 133-142.

[32] Lukashevich N., Svirina A., Garanin D. Multilevel prognosis of logistics chains in case of uncertainty: Information and statistical technologies implementation. Journal of Open Innovation: Technology, Market, and Complexity, vol. 4(1), 2018.

[33] Shabunina T.V., Shchelkina S.P., Rodionov D.G. An innovative approach to the transformation of eco-economic space of a region based on the green economy principles. Academy of Strategic Management Journal, vol. 16(Specialissue1), 2017, pp. 176-185.

[34] Skripnuk D.F., Samylovskaya E.A. Human Activity and the Global Temperature of the Planet. IOP Conference Series: Earth and Environmental Science, vol. 180(1), 2018. 